\title{
Rationing and life-saving treatments: should identifiable patients have higher priority?
}

Tony Hope University of Oxford

\begin{abstract}
Health care systems across the world are unable to afford the best treatment for all patients in all situations. Choices have to be made. One key ethical issue that arises for health authorities is whether the principle of the "rule of rescue" should be adopted or rejected. According to this principle more funding should be available in order to save lives of identifiable, compared with unidentifiable, individuals. Six reasons for giving such priority to identifiable individuals are considered. All are rejected. It is concluded that the principle of the rule of rescue should not be used in determining the allocation of health resources.

(Fournal of Medical Ethics 2001;27:179-185)
\end{abstract}

Keywords: "Rule of rescue"; priority setting; resource allocation; rationing; justice

\section{Rationing health care}

Rationing of health care is a reality in the UK. The National Health Service (NHS) does not have sufficient funds to ensure the very best treatment for all patients in all situations. Choices have to be made. Managed care systems in the US will have to face similar choices. One level within the British NHS at which decisions are made about which treatments to provide is the level of the health authority. ${ }^{1}$ Perhaps as primary care groups and trusts (PCGs and PCTs) develop they will take on an important part of this role.

Daniels and Sabin ${ }^{2}$ have emphasised the importance of the process by which resource allocation decisions are made. They argue that for decisions to be just the process by which the decision is made must be a just one. One feature of such a process is what they call a "relevance condition" - that is, that the rationale for a decision must rest on evidence, reasons and principles that all fair-minded people can agree are relevant. The ethical framework which informs the decision making process is part of such a relevance condition.

It is likely that the courts, at least in the UK, will focus on the procedure by which decisions about health care funding are made. ${ }^{3}$ If a decision is challenged, the health authority, or whichever body is responsible for the decision, may need to justify the decision in two ways:

1. That the process by which the decision was made was appropriate; and,
2. That the reasons for making that particular decision are justifiable.

It remains unclear, however, how courts will address the conflict between treating each patient in her best interests and the scarcity of resources. ${ }^{4}$

\section{Priorities forum-a decision making process}

Oxfordshire Health Authority has developed a procedure for making some resource allocation decisions which meets the criteria laid down by Daniels and Sabin. ${ }^{1}$ A "priorities forum" has been set up to advise the health authority on such decisions. The membership includes general practitioners, medical directors of local hospitals, health authority staff, hospital doctors, nurses and lay members. There are about 30 members altogether. Five are lay members, eleven are non-medical managers, two are university academics and the remainder are health professionals, many of whom have managerial responsibilities. Early in the life of this committee the members felt the need for an ethical framework in order to help it to make decisions in a consistent and well thought out manner. The committee decisions also form a kind of case law-as guidance both for the committee in future decisions, and indeed to enable health authority staff to make decisions without bringing them to the committee. The ethical framework is built around three main considerations: cost effectiveness, equity and patient choice. The most difficult of these for the committee is the interpretation of equity in practical situations.

\section{New and expensive treatments}

Many of the issues brought to the committee arise from new and expensive treatments, especially drug treatments. The setting in which the committee works, and the political realities of health care delivery mean that wholesale changes in what is funded cannot be made. New treatments can be examined, however, and decisions made as to whether, in the context of what can be afforded, the new treatment should be funded at all, and if so, in which groups of patients. Three examples of issues which have been considered by the forum follow.

STATINS

These drugs reduce blood cholesterol with a resulting reduction in the probability of a heart attack or 
sudden death in people with even mildly raised blood cholesterol. The cost per life-year saved depends on what risk of death or of heart attack the person faces in the first place. This risk depends on blood cholesterol level, gender, age, weight and whether the person smokes. For those at an annual risk of heart attack or death of $1.5 \%$, the cost per life-year saved is about $£ 18,000$; for those at $3 \%$ risk it is about $£ 7,000$; and for those at $4.5 \%$ risk it is about $£ 5,000$.

\section{ALGLUCERASE}

Gaucher's disease is a rare inherited disease. There is only one effective treatment: alglucerase. This drug costs about $£ 80,000$ per year per patient.

\section{BETA-INTERFERON}

This drug reduces the relapse frequency in some patients with multiple sclerosis. Its effect (at best) is to reduce the number of relapses from about three to two per year. The cost of the drug has been estimated at between $£ 70,000$ and $£ 500,000$ per quality adjusted life-year.

\section{An approach to decision making}

The priorities forum approaches the question of whether, or to what extent, to fund new treatments in the following way. The starting point for the forum's considerations is the evidence with regard to cost-effectiveness. The forum works best if the members have a clear idea of the situation of the patients who stand to benefit from the treatment and a clear idea of the nature of the benefit using current treatment and the nature of the benefit with the proposed treatment. The beneficial effects of most treatments are not certain to occur in all patients and so the forum is usually dealing with probabilities of these benefits.

The forum, in assessing benefits, considers that length of life and quality of life are of major importance. It therefore finds that the approach using "quality adjusted life-years" (QALYs) is a useful starting point (see for example Williams and Edgar et al. ${ }^{56}$ ) This approach allows a consideration of the length and quality of life amalgamated with both cost and probability of effect.

The approach to reasoning about priority decisions which the forum ideally takes can be outlined as follows:

1. It starts with evidence as to how much the treatment costs per year of life saved (in the case of life-saving or life-extending treatment) or per QALY in the case of other treatments.

2. It compares this with a guide cost - that is the cost that the authority normally pays. Roughly speaking the authority can afford to pay about $£ 10,000$ to $£ 15,000$ per life-year saved.

3. If the proposed treatment is less than this then the forum would normally recommend paying for the treatment. If the proposed treatment is more than this then the forum asks two questions: a) are there grounds for paying more than our usual amount (per life-year saved)?

b) if the answer to this is yes, then the forum asks: do those grounds justify paying that much more?

However, the members of the forum do not, in general, believe that the QALY approach always results in a just or fair result. Some examples of where many members of the forum believe that some deviation from the QALY approach is desirable are as follows.

1. There are situations when, in order to allow an equal quality of service to different groups of people, it may be right to pay more for one group than another. Dental care for people with severe learning disability may be more expensive than for the normal population. However, it may not be right to give a lower priority to such care on the grounds that it is more expensive per QALY.

2. Many believe that the care of the terminally ill should have a higher priority than the QALY calculation suggests.

3. Those who are particularly badly off in terms of their health (for example those suffering from multiple sclerosis) may for this reason merit greater priority than the QALY calculation would consider right.

4. Many people would be prepared to pay more to save the life of identifiable people who are currently ill than to prevent the future death of unidentifiable individuals.

The approach, outlined above, which the forum takes, is useful in practice because it starts with cost-effectiveness data which are both highly relevant and generally available for new drug treatments, at least to some extent. It is an approach which also allows a consideration of many factors other than quantity and quality of life, which may be ethically important in considerations of equity. From the ethical point of view it helps to highlight issues of equality which arise in practice. In this paper I want to consider one such issue: what has been called "the rule of rescue" and what Daniels and Sabin have referred to as "the buried miner". This "rule" is intuitively attractive and operates in practice, for example in forum decisions.

\section{The rule of rescue}

The typical situation is when there is an identified person whose life is at high risk and where there is some intervention ("rescue") which has a chance of saving the person's life. The essence of the value I want to consider is that it is normally justified to spend more on saving life in this situation than in situations where we cannot identify who has been helped. For the sake of clarity I will consider two hypothetical, but realistic interventions.

INTERVENTION A (ANONYMOUS PREVENTION).

$A$ is a drug which will change the chance of death by a small amount in a large number of people. For example, out of every 2,000 people in the group, if 
A is not given then 100 people will die over the next few years. If $\mathrm{A}$ is given then only 99 will die. Drug A is cheap-the cost per life-year saved is $£ 20,000$. Statins provide an example of an intervention of this type.

INTERVENTION B (RESCUE OF IDENTIFIED PERSON) $\mathrm{B}$ is the only effective treatment for an otherwise life-threatening condition. Those with the condition face a greater than $90 \%$ chance of death over the next year if not given $\mathrm{B}$. If given $\mathrm{B}$ then there is a good chance of cure-say greater than $90 \%$. B is expensive. The cost per life-year saved is $£ 50,000$. Renal replacement therapy is an example of an intervention of this type.

The key difference between these two interventions is that intervention $\mathrm{B}$ benefits an identifiable person, whereas intervention A benefits a proportion of patients within a group, but we cannot know who has been benefited.

Let us suppose that the amount of money available to the funding organisation (for example health authority or management care company) allows roughly $£ 15,000$ per life-year saved, on average. Therefore both $\mathrm{A}$ and $\mathrm{B}$ are above the average amount. However, the pressures on a health authority, or other funder, to fund intervention B, can be very great. A particular person whose life can be saved will die if the intervention is not funded. Such a person can take his case to the press or to court.

The question I want to consider is whether it could be right for the funding organisation to choose to fund intervention $\mathrm{B}$ but not intervention A?

For shorthand I will call intervention A the "preventive" intervention, and intervention $B$ the "rescue" intervention. I will consider a number of arguments in favour of paying more, per life-year saved, for the rescue intervention than for the preventive intervention. I will focus on what I think is the strongest of these arguments. I will, however, conclude that this strongest argument is wrong and therefore that it is generally wrong for a funding organisation to pay more for a rescue intervention per life-year saved than for a preventive intervention.

There is one issue which I will not consider in this discussion. No treatment is strictly speaking "life-saving" since none of us is immortal. Treatments at best are death postponing. Some may regard the value of a life-year saved as affected by the age of the person when life is extended. For the sake of the arguments I will consider the age at which interventions $\mathrm{A}$ and $\mathrm{B}$ have their effects as the same.

I will consider six reasons for paying more, per life-year saved, for rescue interventions than for preventive interventions.

\section{Reason 1: scepticism about the} effectiveness of preventive treatment

We can normally be fairly certain of saving the identifiable life (rescue intervention). There may be considerably more scepticism that the preventive treatment really will save lives in the future. This argument, however, is not relevant to most of the situations about funding which are faced by the health authority. Typically the evidence about the effectiveness of the preventive treatment is good. We can be almost certain, for example, that statins will reduce the number of future deaths even though we will never know which individual lives have been saved.

\section{Reason 2: a life in the hand is worth two in the bush}

The treatment of the identified person will typically save a life now, or in the very near future, whereas with prevention we are dealing with saving lives further in the future.

It may be psychologically motivating to consider, as it were, that "a life in the hand is worth two in the bush". However, even if there is justification for some discounting of future lives, ${ }^{7}$ as some economic models hold, this would only justify a relatively small extra cost per identifiable life saved. Furthermore the difference between saving the life of an identifiable person and preventing the death of an unidentifiable person is not fundamentally about whether one is in the present and one in the future. Some preventive treatments (for example drugs reducing the risk of death following a heart attack) prevent (unidentifiable) deaths over the next few days and months; whereas rescue treatments may save life some time in the future.

\section{Reason 3: rescue is rare, so we can always afford it}

Saving the life of an identifiable person is typically rare. We can afford to rescue the occasional person at very high cost - the round-the-world yachtsman who gets into serious trouble, for example; whereas we cannot afford a lower, but still high cost of prevention as that involves many people.

This argument gains its appeal from the fact that when we feel prepared to spend enormous amounts on saving the round-the-world yachtsman we do not imagine that this is at the expense of other people's lives. What we imagine is that the $£, 500,000$ (or whatever) is at the expense of things that others might buy. For example, to pay for saving the yachtsman many people may have to go without some luxury (a good meal in a restaurant, for example). However, in the setting of health care funding, where the money available at any one time is fixed, in paying to save the lives of identifiable people we are using money which might otherwise have been spent on saving more lives by funding a prophylactic intervention.

\section{Reason 4: rescue has more effect on quality of life than prevention}

When we are moved to want to rescue someone, we may be motivated not only by the wish to save life but also by the wish to help people whose death is 
likely to be particularly terrible. The kind of situation we have in mind might be that of a buried miner. Thus the view that we should pay large amounts in these circumstances may be motivated by trying to prevent a particularly appalling quality of life rather than simply preventing death.

In the setting of health care it may sometimes be the case that the rescue treatment has more of an impact on quality of life than preventive treatment, but this will not generally be true. In any case, the funding issue is then about the amount to be spent on improvements in quality of life rather than about extending (saving) life.

\section{Reason 5: it is good to care about identifiable individuals}

There is a considerably different emotional response to a situation where we can identify an individual who may (or is likely to) benefit from a treatment compared with a situation where the person (or people) who benefit cannot be identified.

We are more moved by, and more moved to help in, the former situation than the latter. Many of our moral intuitions are strongly oriented towards individual relationships. These facts have a number of implications for the current discussion.

(a) In our personal morality many would argue that we have different (and greater) obligations to individuals we know (or have some relationship with) than towards people we don't know, or people whom, as individuals, we could not identify. At one extreme, I have much stronger obligations to my children than to other children. In the setting of health care, a doctor, for example, may have a greater obligation towards her own patients than to other patients - the legal concept of "duty of care" underlines this.

It seems unlikely, however, that this is relevant to funding and the health authority (or other large health care funders). A health authority's "duty of care", or that of a managed care company, is presumably to the population which it serves. This includes both those who stand to gain from the preventive intervention and those who benefit from the rescue intervention. Furthermore, the members of the forum, or the health authority more broadly, will not usually know the people who can benefit from "rescue".

(b) There may be broadly consequentialist grounds for a health service spending more (per life-year saved) on rescue than on prevention. If people in general are moved more by rescue than prevention, then a health service which was seen to "rescue" people may attract more support, and therefore more funding, than one which spent no more on rescue than prevention. In the long run, such a health service might be able to carry out more preventive interventions (and more rescue) because it has more funds overall.

Such an argument depends on empirical assumptions which are quite uncertain, and which are likely to vary depending on how the health service is funded and structured. Even if the empirical facts were to support this view, it remains questionable whether a health authority should be affected by them. The role of the health authority, it might be argued, is to spend its money justly and wisely and in the best interests of the population it serves, and not to fund popular causes where to do so is inequitable. On this view the question of what is equitable must be answered independently of what is popular.

A more convincing argument is that a health authority (or managed care system) should respond to the values of its appropriate constituency. If those constituents believe it is right to spend more on rescue than on prevention then it is right (as an element of democracy) for it to do so. I will consider this argument in more detail when I consider the contractualist argument below.

(c) What we do in health care says something important about the kind of society we are. A society which did not rescue identifiable people, but left such people to die would lack solidarity, and would appear cruel and uncaring. It is right therefore for society to be prepared to put much greater resources into rescuing identifiable people, than into prevention-to do so says something important about the kind of society we are.

This argument combines a number of elements, some of which have been considered already. First, it appeals to the "round-the-world yachtsman" view. Surely we ought to be prepared to forego some luxuries to save a person's life. Second, it raises the whole question of how much overall we ought, as a society, to be prepared to spend to save life. The more caring society would give up many luxuries to help those whose lives are at risk. But, in my view, this argument essentially begs the question at issue. Is it a more caring society which sacrifices several (anonymous) lives which might have been saved (by a preventive intervention) in order to save one identifiable life (through "rescue")?

In the case of rescue we can identify and imagine the particular individual, and the relatives and friends who will be bereaved. This engages our sympathy. But in the case of prevention, although we know that our choice will lead to several deaths - and many more relatives and friends being bereaved-because we do not know which individuals, our sympathy is not engaged. Those who choose to save the more lives through preventive intervention may be regarded as cold-hearted on the grounds that they fail to be properly moved by the individuals who thereby do not receive rescue intervention. But the argument could be reversed. It is not that the first group are not moved by the plight of those needing rescue, it is that the second group are not sufficiently moved by the fact that there are a larger number of people who die, and who are bereaved, as a result of paying more, per life-year saved for rescue than for prevention. The callousness lies in the relative indifference to death and suffering simply because the specific individuals concerned cannot be identified. There is a lack of imagination in those preferring rescue rather than a lack of sympathy in those preferring prophylaxis. 
In order to decide which side is right in this debate, I think that first the question of whether the "rule of rescue" is right has to be answered. Thus, the "argument from callousness" stated above cannot be used to support the rule of rescue. The argument depends on having established that it is a good society, or a fair society, which would follow the rule of rescue.

\section{Reason 6: a very small decrease in the chance of death is of only small benefit}

The most powerful reason in support of paying more to save the identified life, I believe, is that in the typical cases of prevention the intervention makes only a small difference to the probability of death of any one individual whereas in the typical example of rescue (but by no means in all examples) the intervention makes a large difference to one or more individuals. This enables a broadly "contractualist" argument to be mounted in favour of the rule of rescue. I will try and put this argument in as strong a form as possible.

Premature death is, normally, a very significant harm indeed. It is partly because of this that good health care is so important. Preventing premature death is a paradigm of what Daniels calls a need ${ }^{8}$ more than almost anything else it interferes with our life goals and opportunities.

But a very small chance of premature death is by no means a great harm - and we cannot claim that we need something which reduces by a very small amount the chance of premature death. All of us in our lives trade small increases in the chance of premature death against really quite small benefits. Consider Peter, the Sunday morning cyclist.

\section{The Sunday morning cyclist}

On Sunday mornings Peter cycles along the busy Banbury Road, in Oxford, to buy a newspaper. In doing this he is putting himself at a small but real extra risk of premature death. $\mathrm{He}$ is trading this extra risk against the pleasure and value of reading the Sunday morning paper. In balancing these two he finds that the pleasure of the paper-a really rather small pleasure in his life-outweighs the extra risk of premature death. There seems nothing irrational about this. A very small chance of a terrible harm is itself only a small negative weight easily outweighed by other benefits. Most of us will take these small risks not only for our own benefit but for the benefit of others. Consider the friend's job application.

\section{The friend's job application}

Suppose that David's friend Sarah is applying for a job which she is keen to get. To meet the deadline the application has to be in the postbox today. Owing to a severe bout of 'flu, Sarah cannot post it herself. To help her, David cycles to Sarah's house to collect the application and post it. This action increases by a very small amount David's chance of premature death. This is easily outweighed by the value of helping Sarah.
With these considerations in mind I will propose a three-stage argument in favour of the health authority's paying for intervention B (at a cost of $£, 50,000$ per life-year saved) but not for intervention A (at a cost of $£ 20,000$ per life-year saved):

1. A very small increase in the risk of premature death represents only a small consideration to weigh against the benefits.

2. It is rational to trade that small extra risk in order to make a small but definite contribution towards saving someone else's life.

3. In practice this is likely to be what most people would choose and this therefore forms contractualist grounds for a health authority (or other health care purchaser) to operate a rule of rescue.

I will now consider a counterexample to this conclusion: the case of the trapped miner.

\section{The case of the trapped miner}

A miner lies trapped following an accident. Without rescue he will die. Given a sufficiently large rescue party the miner can be rescued. Would you, the reader, join the rescue party if you faced a $1: 10,000$ risk of death in so doing? Would your answer depend on the size of the rescue party needed?

Suppose the facts (perhaps not entirely realistic) are these: there is a small risk of death to those in the rescue party, and this risk varies according to the size of the rescue party. If there were 1,000 rescuers there would be a $1: 1,000$ chance for each rescuer of death. If there were 10,000 rescuers each would face a 1:2,000 chance of death. If 100,000 rescuers then each would face a $1: 10,000$ chance of death. If $1,000,000$ then each would face a $1: 20,000$ risk.

Thus the larger the size of the rescue party, the smaller the risk of death faced by each individual rescuer. It is also the case, however, that the larger the size of the rescue party, the more people are likely to die in the rescue attempt. With a rescue party of 1,000,000 each member of the rescue party faces a very small risk of death-well within the risks we normally take for much less important gains than saving a life. However, with such a rescue party about 50 people will die in order to save the life of one person.

If we assume that most people are altruistic at least to a small extent, and most people will accept a very small level of risk of personal death in order to save another's life; and if we assume further that most people, given the choice, would like to face as low a personal risk of death as possible, then respecting the wishes of each potential member of the rescue party would have the following result. The wishes of potential members of the rescue party would be most respected by putting together an enormous rescue party in order to save the trapped miner - at the expense of many lives.

Thus, if the issue of rescue is seen simply as a question of balancing individual risks for each rescuer against the benefit to the individual of being 
rescued, then it would seem right to pursue a policy which overall was very costly in terms of lives lost. Suppose, for example, that the rescue was being led by a senior army officer. If that army officer were to coordinate the rescue, with the foreseeable result that more people would die in the attempt to rescue than would be saved by the rescue, then the army officer might reasonably be criticised. One reason for such criticism might be that those in the rescue party had no choice but to join in because they had to obey their senior officer. However, if the rescue party were made up of volunteers who knew and accepted the risk to themselves, then might it not be justified to organise a rescue which will foreseeably lead to more deaths overall? The justification would be that fully competent adults in possession of all relevant information have made an individual choice to take part in the rescue party.

The case of the trapped miner, as outlined above, demonstrates, I think, that at the very least the volunteers would need to know not only the individual risk of death which each faces, but also the overall size of the rescue party. It would need to be made clear to the volunteers that the rescue itself will result in more deaths amongst the rescuers than the number of people who will be saved. This information is likely to affect potential volunteers' views on whether or not to join the rescue party.

In any case, returning to the situation which faces the health authority, it is not clear that those who could benefit from the preventive treatment have voluntarily agreed to forego their treatment in order for identifiable patients to receive expensive lifesaving treatment. In other words, if the health authority spends more per year of life saved on rescue treatments than prophylactic treatments, the health authority is effectively volunteering those who would benefit from the preventive treatment to take part in the rescue party. Because of limited resources, the health authority in making any of its decisions about treatments which save lives, has to save some people's lives at the expense of other people's lives. In the absence of a clear mandate from the group of people who stand to lose by a particular decision, it seems to me that the core principle must be that those decisions should be taken which overall save more lives.

\section{Why the contractualist theory in favour of rescue fails}

A contractualist theory might lead to the view that although there is no explicit mandate (ie there has been no explicit volunteering) from those who would benefit from preventive treatment, this is nevertheless what the population would want. In other words, the argument is that the population, say of Oxfordshire, would favour the health authority spending more money to save the lives of identifiable people, thus leading overall to more lives lost through a failure to fund preventive treatments. On this argument it is supposed that most of the population, including those who might benefit from the preventive treatments, would trade the very small increased risk of death (from failure to fund the preventive treatment) for the benefit of rescuing identifiable people. However, if this argument is to be put forward I think that a number of points would need to be clarified.

1. In collecting the evidence, it would need to be made clear that overall more lives would be lost.

2. Even if there were good evidence that this is what people would want there is still the question of whether it is right for the health authority to sacrifice more lives for fewer lives. In the case of the trapped miner, even if it were possible to find a large number of volunteers to join the rescue party in full knowledge both of their personal risk and that overall more lives would be lost, it remains questionable whether an authority should organise such a rescue party.

3. A contractualist defence may make use of Rawls's "veil of ignorance" approach. ${ }^{9}$ On this approach Rawls asks us to imagine a whole range of different societies. We can choose which society to join, but we do not know who we will be in the society. In the present context, the two societies under consideration would be one where a health authority (or rescue party) spends more per life-year saved on rescue than on prevention; and the other would be a society which gives equal priority to prevention. Behind the veil of ignorance we are asked which we would choose. If the veil of ignorance approach is taken to be a genuine empirical questionthat is a question as to what people as a matter of fact would choose, given this hypothetical situation, then we simply do not have the empirical facts to know what most people would choose. I imagine there would be considerable variation. If, on the other hand, the veil of ignorance approach is taken to be a method of clarifying the conceptual issues around justice, then it would seem to favour giving no priority to rescue. That is, it would seem most just to choose the society where, overall, our chance of death is least.

I conclude that in the absence of a clear mandate from society, and possibly even if there were such a mandate, it is wrong for a health authority to pay more per life-year saved by rescue than by prevention.

\section{Acknowledgements}

I would like to thank Dr John Reynolds for information on new drugs, Professor Siän Griffiths for discussions of rationing procedures and Professor Julian Savulescu and Dr Roger Crisp for detailed discussion of the principles and arguments.

Tony Hope MA, PhD, FRCPsych, is Professor of Medical Ethics at the University of Oxford and Director of the Ethox Centre. 


\section{References}

1 Hope T, Hicks N, Reynolds DJM, Crisp R, Griffiths S. Rationing and the health authority. British Medical fournal 198317:1067-9.

Daniels N, Sabin J. Limits to health care: fair procedures, democratic deliberation and the legitimacy problem for insurers. Philosophy and Public Affairs 1997;26:303-50.

3 Montgomery J. Health care law. Oxford: Oxford University Press, 1997

4 Savulescu J. The cost of refusing treatment and equality of outcome. Fournal of Medical Ethics 1998;24:231-6.
5 Williams A. QALYs and ethics-a health economist's view. Society for the Science of Medicine 1996;43:1795-804.

6 Edgar A, Salek S, Shickle D, Cohen D. The ethical OALY - ethical issues in healthcare resource allocations. Haslemere, UK: Euromed Communications Ltd, 1998.

7 Savulescu J. The present-aim theory: a submaximizing theory of rationality? Australasian fournal of Philosophy 1998;76:229-43.

8 Daniels N. Fust health care-studies in philosophy and health 8 Daniels N. Fust health care-studies in philosophy and

9 Rawls J. A theory of justice. Oxford: Oxford University Press, 1972 .

\title{
Hippocrates invents continuing medical education ${ }^{1}$
}

\author{
Edward V Spudis Forsyth Medical Center, Winston-Salem, North Carolina, USA
}

First let's thank the Spart-Davis rep for supplying the olive dip and wine, while we discuss what we could have done differently at Thermopylae. We learned from Menades' 2000-ducat grant that the left-handed Turkish corpses also had hearts on that side. And, the icteric eyes may be prized by the older alcoholics, but "licking blood forego, if their eyes are calico".

Herophillus insists that ideas come from the brain to either[ital] sword arm down through the neck. Well, necks must be important, but it depends on your Democratic definition of come from.

The one-size-fits-all supporter will soon be off the stylus board.

And, for war paint use benzyl penicillium, or maybe Corinthian imodium; our single-blind trials have rejected meconium.

(NB: For Olympian Education Credits scratch this slate on the way out.)

Edward V Spudis, MD, is Senior Neurologist at the Forsyth Medical Center and Clinical Professor Emeritus at Wake Forest University Medical School, Winston-Salem, North Carolina, USA.

\section{Reference}

1 du Boulay C. Revalidation for doctors in the United Kingdom: the end of the beginning? British Medical fournal 2000;320:1490. 